\title{
Mechanical Properties of the Chick Embryo Spinal Cord \\ By
}

\section{Ragi Ahdi Ibrahim Elias}

\author{
A Thesis submitted to the \\ Graduate School - New Brunswick \\ Rutgers, The State University of New Jersey \\ and \\ The Graduate School of Biomedical Sciences \\ University of Medicine and Dentistry of New Jersey \\ In partial fulfillment of the requirements \\ for the degree of \\ Master of Science \\ Graduate Program in Biomedical Engineering \\ written under the direction of \\ Dr. David I. Shreiber \\ and approved by \\ NEW BRUNSWICK, NJ \\ OCtobeR, 2007
}




\section{ABstRact OF THE THESIS \\ Mechanical Properties of the Chick Embryo Spinal Cord \\ By Ragi Ahdi Ibrahim Elias \\ Thesis Director: \\ David I. Shreiber}

The mechanical properties of the spinal cord dictate its response to traumatic loading conditions, and also provide important cues to cellular constituents that regulate behavior such as growth and differentiation. After initial connections are established, the structure and composition of the human spinal cord continues to significantly change during development, both pre-natally and during the early years of life. As such, the mechanical properties of the spinal cord are likely to also change, which would potentially alter both the physical tolerance of the spinal cord to injury as well as the regulatory mechanostructural cues that encourage or inhibit neural differentiation and axon growth.

Previous studies have quantified the properties of fully developed adult spinal cords from the rat, cat and human. This study quantifies the mechanical properties of the chick embryo spinal cord during a period of rapid growth and development which partially parallels the development of the post-natal human infant.

Quasistatic uniaxial tensile testing to failure was performed on chick embryo spinal cords at $0.001 \mathrm{~s}^{-1}$. Samples were tested at embryological days (E) 14, 15, 16 and 18. Spinal cords demonstrated non-linear stress-strain behavior that was modeled with a 1-term Ogden hyperelastic strain energy density function. Stiffness and ultimate tensile stress (UTS) were observed with increasing development. 
Stress-relaxation viscoelastic testing was also performed on spinal cords from the same development days at a loading rate consistent with those experienced during trauma (ramp to $7.5 \%$ stretch at $\sim 19.5 \mathrm{~s}^{-1}$ and hold for 10 seconds). All spinal cords demonstrated significant relaxation, and the behavior was modeled with a linear series of 4 exponential decay time constants. Statistical analysis indicated that the viscoelastic properties did not change between the days tested. Regardless of the maximum stress reached from the ramp phase, all cords tested relaxed $\sim 72.5 \%$ with $\sim 68 \%$ of this relaxation occurring within the first $30 \mathrm{~ms}$. The changes in the stiffness and UTS in the developing chick embryo spinal cord suggest similar changes in the developing human spinal cord, which points to the need for age-specific injury tolerance criteria. 


\section{ACKNOWLEDGEMENTS}

The Lord is my rock and my fortress and my deliverer; My God, my strength in whom I will trust; My shield and the horn of my salvation, my stronghold.

Psalm 18:2

First and foremost I must always thank the Lord my God

Thanks to my parents of whom I am so proud. Words will never do justice to how I feel about you

Thanks to my brother Fadi Elias who has always held me with great regard and love of which I am not worthy $\sim$ I love you

Much thanks to Dr David I. Shreiber who has been an exceptional Professor, Advisor, and Friend throughout my years at Rutgers. Your guidance will never be overlooked or forgotten.

Thanks to the Shreiber Lab Group for their help and friendship

Thanks to my boys Peter Sleman, Mark Tanios, Beshoy Sharoupim and Waleed Mina who have kept me sane despite my driving them crazy with the words "chicks" and "testing"

Thanks to my Grandmas back home who never stop praying for me and to the rest of my Family in Egypt who bring so much joy to my heart 


\section{TABLE OF CONTENTS}

Abstract OF THE THESIS ii

ACKNOWLEDGEMENTS .................................................... iv

INTRODUCTION....................................................................... 1

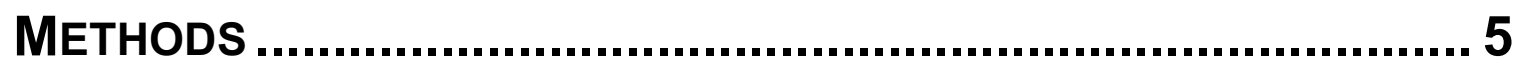

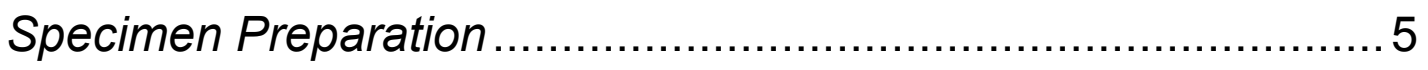

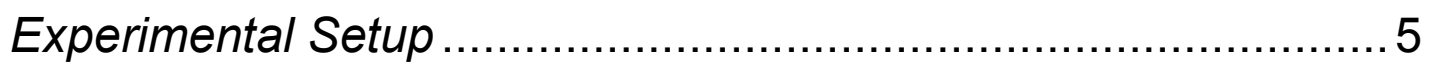

Mechanical Testing Procedure ............................................... 6

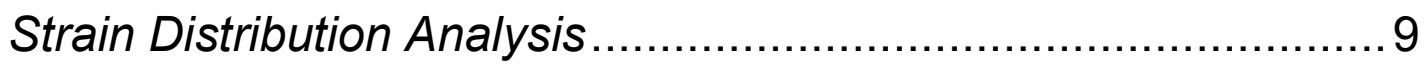

Spinal Cord Constitutive Modeling.............................................11

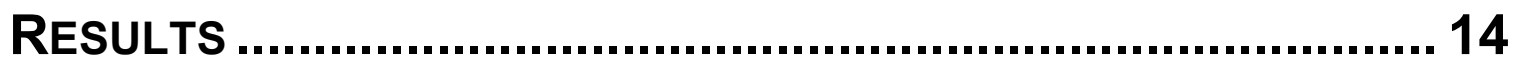

Strain Distribution Uniformity ................................................. 14

Spinal Cord Quasi-Static Testing Response ............................... 14

Spinal Cord Viscoelastic Testing Response .............................22

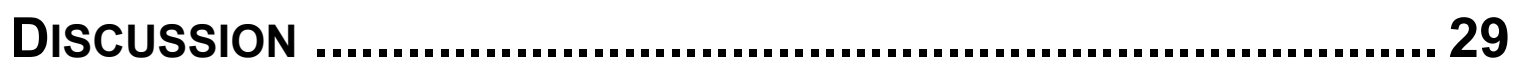

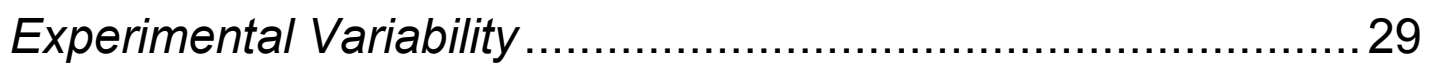

Spinal Cord Quasi-Static Testing.............................................. 31

Spinal Cord Viscoelastic Testing ............................................. 34

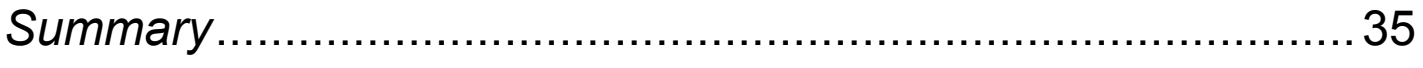




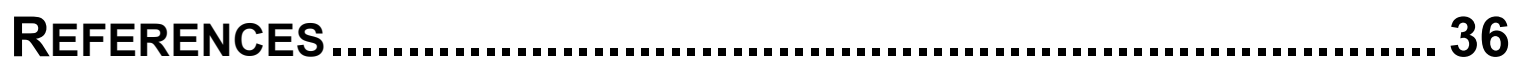




\section{LIST OF TABLES}

Table-1: Strain Distribution Uniformity .................................15

Table-2: Spinal Cord Ultimate Tensile Stress \& Stretch ............18

Table-3: Spinal Cord Ogden Hyperelastic Constants ............... 19

Table-4: Spinal Cord Viscoelastic Constants. .......................27 


\section{LIST OF ILLUSTRATIONS}

Figure-1: Enduratec Mechanical Testing Setup ......................... 7

Figure-2: Schematic of the Spinal Cord Layout in the ELF .......... 8

Figure-3: Strain Uniformity Segment Assessment .................... 10

Figure-4: Representative Stress-Stretch Ratio Quasi-static

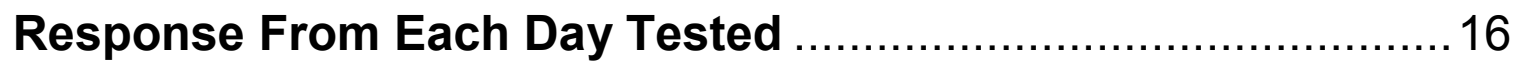

Figure-5: Averaged Ogden Parameter Fits For Each Day ….......20

Figure-6: Average Ogden Hyperelastic Material Constants .......21

Figure-7: Viscoelastic Test Commanded Function vs Actual

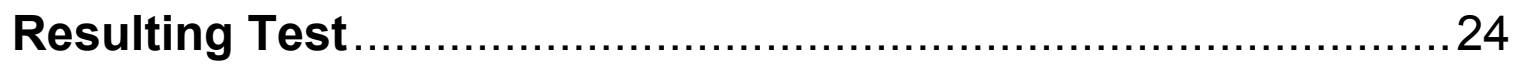

Figure-8: Representative Viscoelastic Stress Relaxation

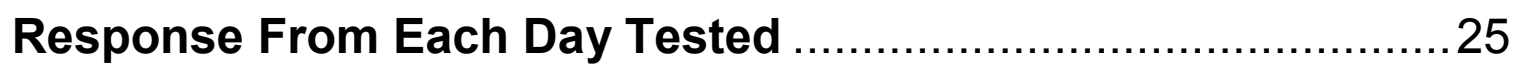

Figure-9: Representative Viscoelastic Ramp Response From

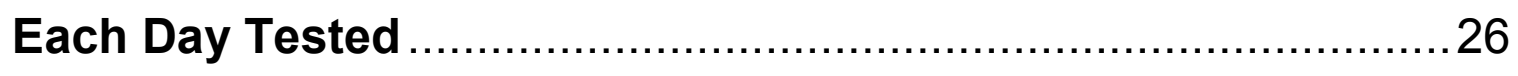

Figure-10: Averaged Prony Series 4-Term Exponential Decay

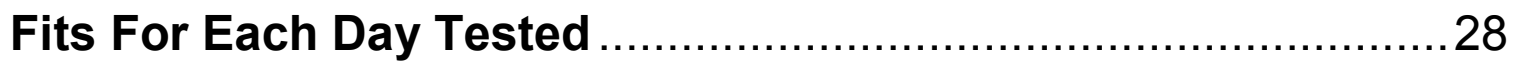




\section{LIST OF NOMENCLATURE}

$\boldsymbol{W}$ - Ogden Strain Energy Potential

G - Shear Modulus

$\boldsymbol{\alpha}$ - Measure on non-linearity

$\boldsymbol{\lambda}$ - Stretch Ratio

$\boldsymbol{\sigma}$ - Nominal Stress

g - Relative Relaxation Constant

$\tau$ - Relative Time Decay Constant

$L_{0}$ - Initial Length

$L_{s}$ - Spine Length (In-Situ Length)

$\mathrm{L}_{\mathrm{sc}}$ - Spinal Cord Length (In-vitro Length)

UTS - Ultimate Tensile Stress 


\section{INTRODUCTION}

The mechanical properties of the spinal cord dictate its response to injurious loading conditions, and therefore are necessary in predicting injury tolerance criteria. In accurately predicting age-specific injury tolerance criteria, an adequate description of age-specific material characteristics is necessary [13]. Since age-specific changes in biological constituents correspond to changes in material properties, understanding the developing spinal cord's unique mechanical response to load is critical in predicting tolerance to injury [25].

In addition to solely predicting spinal cord injury tolerance, real treatment often requires the restoration or replacement of missing or dysfunctional neurons [20]. Advances in neural stem cell research for therapy following brain or spinal cord injury and treating neurodegenerative conditions (such as Parkinson's disease), have shown that cells respond to a myriad of signals. These signals, which include the mechanical properties of the environment in which they grow, are necessary in order to appropriately divide, differentiate and migrate [12]. Neuronal cells specifically appear to be exquisite biosensors of mechanical rigidity, and are able to generate different branching densities over a fairly narrow range of substrate deformability [12].

Therefore, for both the prediction of age-specific spinal cord injury tolerance as well as treatment options, age-specific mechanical properties of the spinal cord are essential. In the human, Calder et al. have shown that during embryological development and continuing into the first years of life, the central nervous system undergoes a period of accelerated growth and development. For example, neurons exhibit significant alterations in dendritic and axonal branching, which is accompanied by a rise in myelination [8]. Consequently, since the properties are changing with growth 
and development, fetal or pediatric developing spinal cord material properties cannot be properly modeled by those of the fully developed adult spinal cord.

Spinal cord mechanical properties have been previously quantified for adults in a variety of species including rats, cats, and human. Most recently for example, Fiford and Bilston tested the mechanical properties of adult Lewis rat spinal cords [11]. The timedependent mechanical properties of the adult spinal cords were investigated at low to moderate strain rates $\left(.002, .02\right.$, or $\left..2 \mathrm{~s}^{-1}\right)$ and showed failure strains of approximately $12 \%$, corresponding to a stress of about $80 \mathrm{kPa}$ [11]. Prior, the time-dependent mechanical properties of the human spinal cord had also been tested [5]. Cervical and thoracic human spinal cord specimens for that particular study were obtained from adults age 30-84 years [5]. For the three different strain rates run, $0.048 \mathrm{~s}^{-1}, 0.120 \mathrm{~s}^{-1}$, and $0.225 \mathrm{~s}^{-1}$, the average elastic moduli were $1.02 \mathrm{MPa}, 1.17 \mathrm{MPa}$, and $1.37 \mathrm{MPa}$ respectively [5]. However, to the best of our knowledge, the dependence of these properties on growth and development remain unknown. Therefore, the objective of this study is to determine the mechanical properties of the spinal cord along different days of the embryological development period.

To examine these changes during development, the chick embryo model was chosen as the surrogate for several reasons. First, chick embryo spinal cords were easily available through incubation of fertile eggs and were the most cost effective. They have also been a commonly used surrogate for developmental studies ever since Aristotle "discovered" the chick embryo as an ideal object for embryological studies [14], largely because the chick embryo develops and hatches in a mere three weeks (E0 E21). This eliminates the typical delays associated with investigating different stages of development, which would arise if other surrogates were chosen. It also correlates to comprehensive changes in development from day to day according to the established Hamburger and Hamilton chick embryo developmental stages [14]. 
Furthermore, a major factor in favor of the chick is that the development of the chick embryo while still in ovo, partially parallels the continued development of the postnatal human infant. According to the Witschi standard staging of embryological development, the chick is in developmental stage 35 from E13 to E18 and the rat is in the same developmental stage 35 from its last 3 pre-natal days up to its $16^{\text {th }}$ post-natal day $[1,28]$. Additionally, studies have shown that the rat at $12-15$ postnatal days of age is neurologically equivalent to a 2-3 year old human child [10,22]. Therefore, the chick embryo development from E13 onwards, is equivalent to that of the human infant in its first years of life.

We have previously characterized the kinematic response of axons in the chick embryo spinal cord to controlled, quasistatic stretch from E12-E18, and found that axons in spinal cord white matter demonstrate increasingly affine, or coupled mechanical behavior as development progresses [16]. The results strongly suggest that the mechanical properties of the spinal cord change with development, but the effects of this micro-scale behavior on macroscopic mechanical properties are not known.

To begin relating the micro-scale observation to macro-scale behavior, the mechanical properties of chick embryo spinal cords were evaluated at fourteen, fifteen, sixteen and eighteen days along in development (E14, E15, E16, \& E18). Along with the knowledge that E13 onwards parallels the development of the human infant in its first years, analysis of blood vessels has shown that the chick embryo's spinal cord blood supply becomes much more elaborate and branched after E13 [27]. Thus, spinal cord developmental changes were expected to be greatly increased after E13. Spinal cords younger than E14 however, were increasingly difficult to dissect and test properly. Moreover, the formation of compact myelin around axons is significantly different between $\mathrm{E} 12$ and $\mathrm{E} 18$ [2]. At E12, only $1 \%$ of all axons are surrounded by compact myelin. By E15 approximately $16 \%$ of all axons are myelinated, and more than half of 
them are myelinated by E18 [2]. We believe that such a progressive change in this biological constituent will contribute to altering the cord's mechanical properties.

The samples from each of these chosen developmental days were all tested uniaxially in-vitro. First, a tensile quasi-static test was run at $0.001 \mathrm{~s}^{-1}$ until failure. This low strain rate is lower than those estimated to occur during normal motion [5]. A time dependent stress relaxation test was also performed on cords from all the same development days used for the quasi-static test. The cords in this test were ramped to $7.5 \%$ strain at $245 \mathrm{~mm} / \mathrm{sec}\left(\sim 19.5 \mathrm{~s}^{-1}\right.$ strain rate $)$ and held for 10 seconds. To the best of our knowledge, no spinal cord mechanical testing has been done at such a fast rate. Performing stress relaxation tests at this rate was very important in simulating trauma and providing the resulting response of the spinal cord. This study will show how the spinal cord quasi-static properties change from E14 to E18 as well as how the viscoelastic properties do not. 


\section{METHODS}

\section{Specimen Preparation}

Fertilized chick embryo eggs (Charles River Laboratories, North Franklin, Connecticut) were incubated upon arrival at $37^{\circ} \mathrm{C}$ and $100 \%$ humidity. The eggs were then removed for testing at fourteen, fifteen, sixteen, or eighteen days later corresponding to E14, E15, E16 or E18 of development. To isolate the spinal cord, the laminae were removed from the cervical region to the sacral region. With the spinal cord still attached inside, the length of this region of the spinal column was then measured with digital calipers. The spinal cord was then carefully removed from the spine and visually checked under the microscope for any abnormalities or damage that may have occurred during its removal. The length of the extracted spinal cord length was subsequently measured with the same digital calipers. The two measured lengths corresponded to in-situ and in-vitro lengths respectively. Twelve millimeters of the spinal cord (mainly thoracic region) were used for testing and the ends of the $12 \mathrm{~mm}$ segment were precisely marked off with two dots of glitter. Three more dots were also placed along the spinal cord surface within the same $12 \mathrm{~mm}$ region. These markings allowed for assessment of strain uniformity during testing. Major and minor axes of the cord were also measured within the region that was tested with digital calipers. Measurements were taken upon initial contact with the tissue before any obvious compression occurred [7] and the area of the spinal cord was calculated as an ellipse [11].

\section{Experimental Setup}

Uniaxial testing of the chick embryo spinal cord was performed using a Bose/Enduratec uniaxial testing machine (ELF 3200, Electroforce Systems Group of Bose Corporation, Eden Prairie, Minnesota) operating in a horizontal configuration. A $0.5 \mathrm{~N}$ cantilever Entran load cell (Measurement Specialities, Hampton, VA) was chosen 
as a proper load cell for all of the four development days studied. As shown in Figure 1, two polyethylene plates were placed 10 millimeters apart in the Enduratec $(2 \mathrm{~mm}$ shorter than the marked region on the cord). One plate was bolted onto the cantilever of the load cell (which was calibrated with this plate on), while the other plate was gripped by the crosshead. The spinal cord was then laid onto the plastic plates with one end of the previously marked $12 \mathrm{~mm}$ segment placed exactly at the edge of plastic plate attached to the cross head while the other end of the marked segment was placed exactly at the edge of the plastic plate attached to the load cell. Consequently, as shown in Figure 2, the cord in this setup was not being stretched when originally placed in the Enduratec. The spinal cord ends were then fixed to the two plastic plates via "Loctite Super Glue" cyanoacrylate adhesive (Henkel Consumer Adhesives, Inc., Avon, OH) and left to dry for approximately 30 seconds while maintaining the hydration of the cord in between. Hydration of the samples was maintained throughout the entire testing process with an ultrasonic mister (Wachsmuth \& Krogmann, Elk Grove Village, IL). Preliminary studies indicated that the use of a continuous mist greatly improved repeatability of experiments vs. intermittent spray. A Samsung Digimax 4500 digital camera was also secured to the top of the Enduratec looking straight down onto the spinal cord being tested. Pictures were taken every $0.5 \mathrm{~mm}$ to asses strain uniformity distribution (Microsuite analysis software, Olympus Scientific, Melville, NY).

\section{Mechanical Testing Procedure}

Each sample was only tested once and all tests were performed at room temperature. To assess quasi-static properties of the spinal cord, the spinal cords were uniaxially stretched to failure at a $0.012 \mathrm{~mm} / \mathrm{sec}$ corresponding to an approximate $0.001 \mathrm{~s}^{-1}$ strain rate. Due to the delicacy of the tissue no preconditioning was applied [21], which is consistent with other CNS tissue. The Wintest acquisition program was used to record time elapsed, displacement and load, and the data was fit to a 

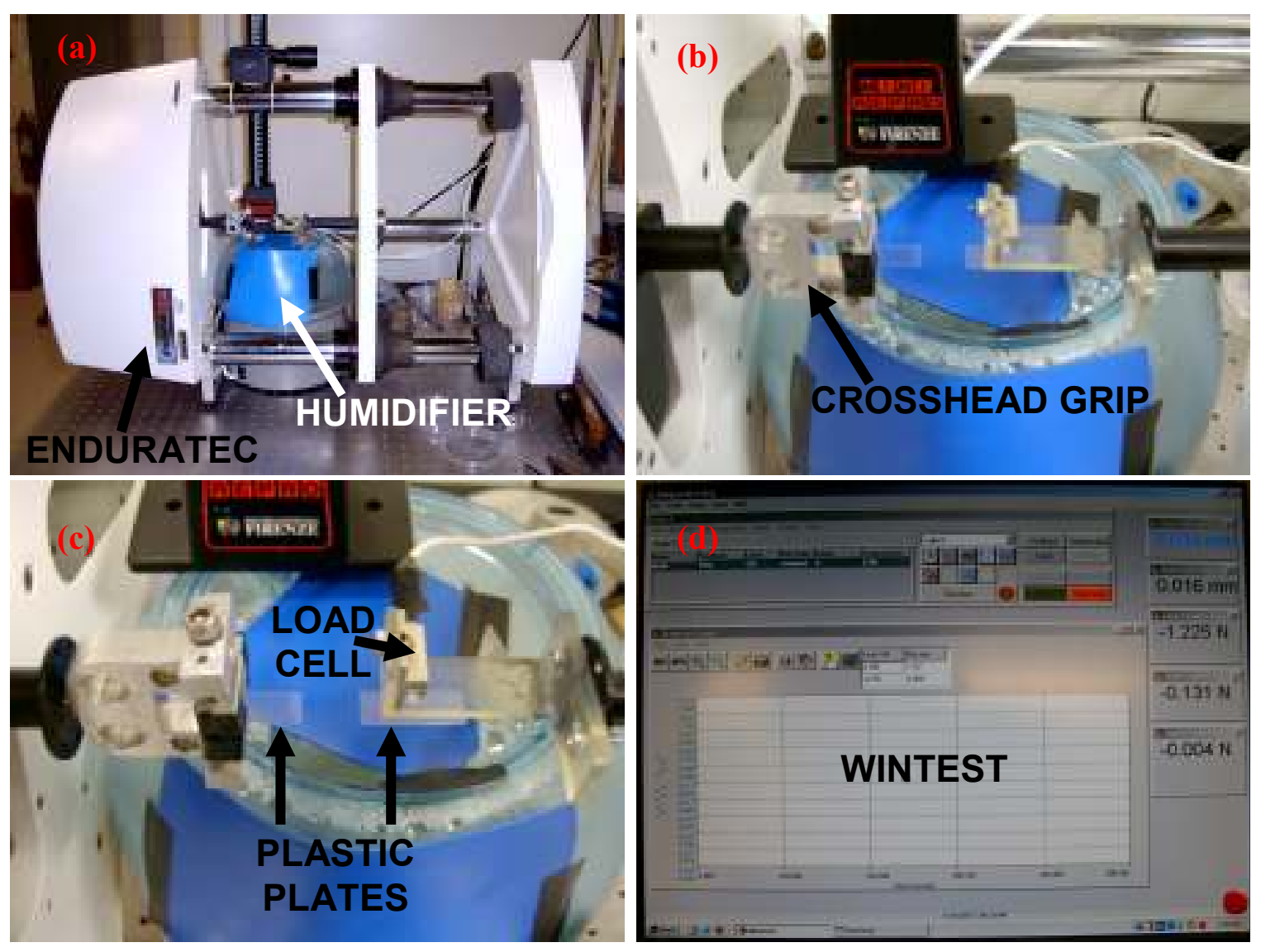

Figure-1: (a) The Enduratec ELF 3200 used for mechanical testing. (b) The crosshead grip. (c) The $0.5 \mathrm{~N}$ load cell and the attached plastic plates. (d) The Wintest acquisition program accompanying the Enduratec. 


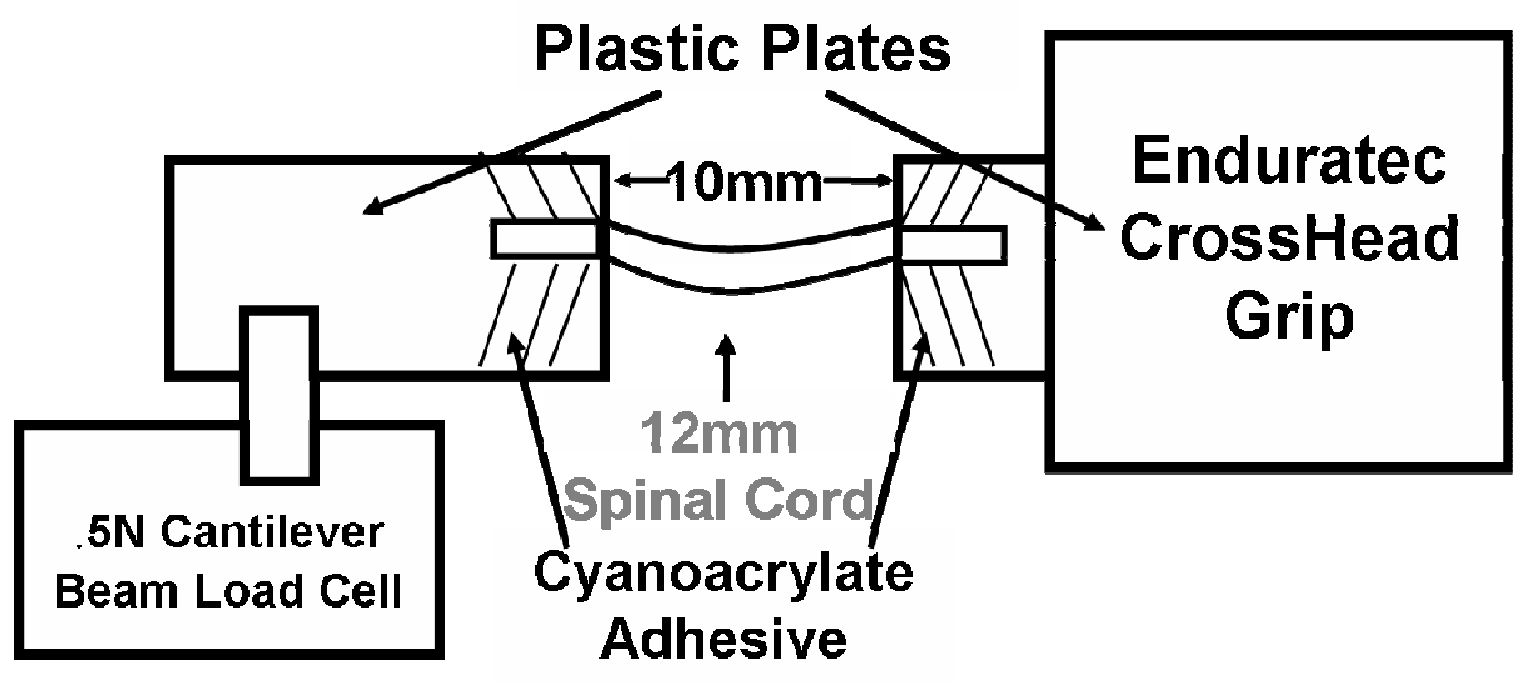

Figure-2: Schematic of how the load cell, the crosshead grip, the plastic plates, and the spinal cord were oriented for testing. The spinal cord maintained a small degree of slack when initially placed into the setup. 
1-term Ogden hyperelastic strain energy function using Kaleidagraph (Synergy Software, Version 3.52, Reading, PA). To examine the material properties of a time scale relevant to traumatic spinal cord injury, stress relaxation viscoelastic testing was also performed. Samples were uniaxially stretched to $7.5 \%$ strain at an extremely high strain rate of $19.5 \mathrm{~s}^{-1}(245 \mathrm{~mm} / \mathrm{sec})$ and held for 10 seconds. Data for this test was fit to a 4-time constant Prony Series exponential decay function using Kaleidagraph.

Kaleidagraph is a curve fitting program that fits the data based on a sum of least squares method. First, the fitting function and maximum allowable error are input along with initial guesses for the constants requiring calculation. Starting with the initial guesses, Kaleidagraph then iterates through the data and determines values for these constants until they fall within the allowable error range. An allowable error of $0.1 \%$ was used in this study.

\section{Strain Distribution Analysis}

Strain distribution uniformity along the length of the spinal cord region being stretched was analyzed by measuring the initial and final lengths of each of the regions formed by the markers in half millimeter increments. As shown in Figure 3, the markers split the spinal cord into 4 segments. For each segment the stretch ratio was calculated and normalized to the overall stretch ratio of the spinal cord. The closer each of these normalized values were to 1 , the more uniform the strain along the length of the cord [3]. 


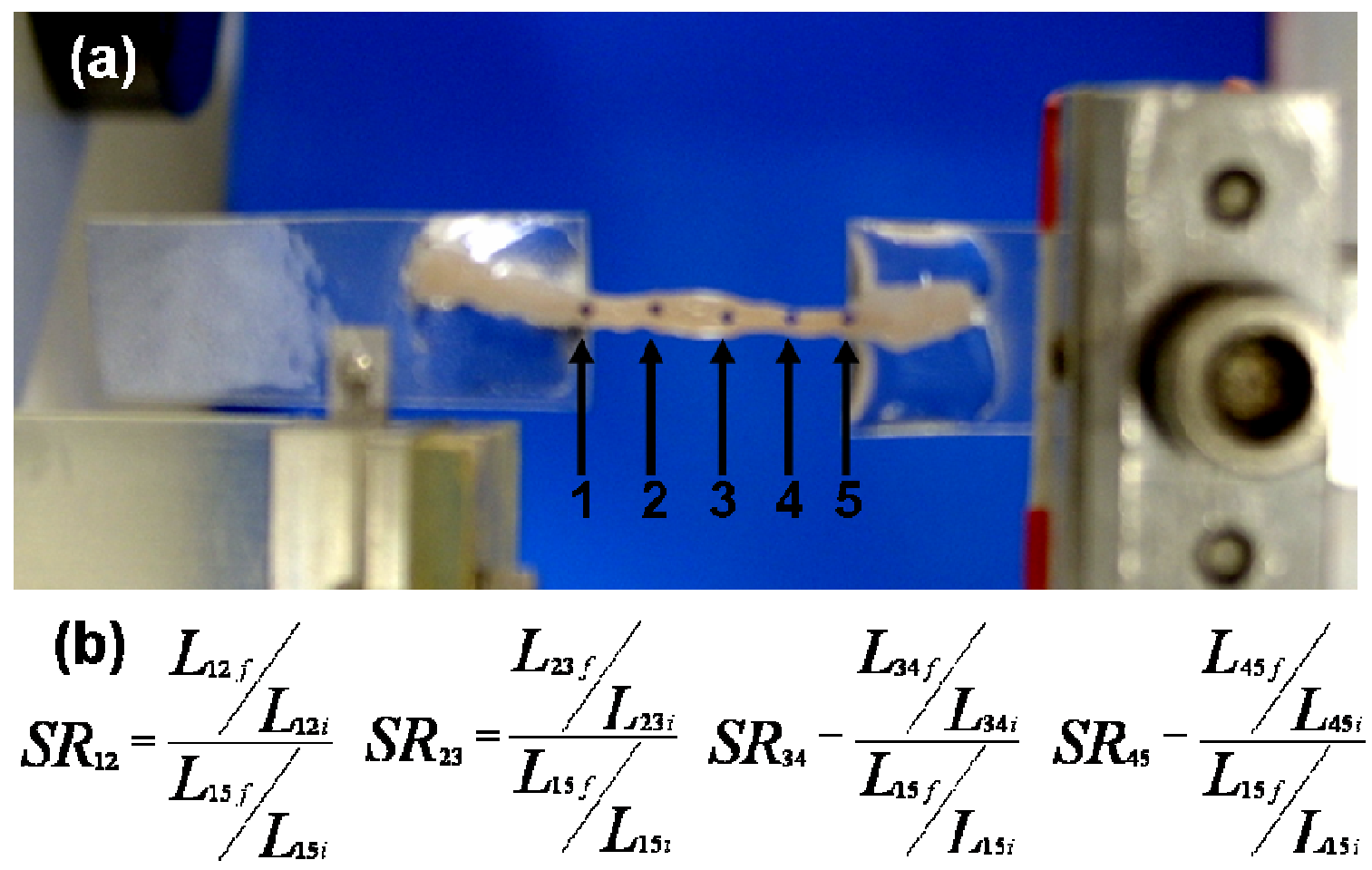

Figure-3: (a) An example of how the markers were laid onto the spinal cord for strain uniformity analysis. (b) The formulas used for calculating and normalizing the stretch ratio for each segment. 


\section{Spinal Cord Constitutive Modeling}

The spinal cord was modeled as a hyperelastic linearly viscoelastic continuum. At both quasi-static and viscoelastic rates the spinal cord behaved hyper-elastically. For the quasistatic modeling, the Ogden form of the hyperelastic strain energy potential function $(W)$ was used to characterize the spinal cord as done in previous studies $[5,21]$. Equation 1 shows the general Ogden function:

$$
W=\sum_{i=1}^{N} \frac{2 G_{i}}{\alpha_{i}^{2}}\left(\lambda_{1}^{\alpha_{i}}+\lambda_{2}^{\alpha_{i}}+\lambda_{3}^{\alpha_{i}}-3\right) \quad \text { Equation } 1
$$

The $\lambda_{i}$ in the equation are the deviatoric principal stretches and $N$ is the complexity of the law. The $\Sigma G_{i}$ represent the shear modulus and $\Sigma \alpha_{i}$ are also a material-dependent parameter. In the case of uniaxial tension, the relationship between nominal stress and stretch ratio for an Ogden material is:

$$
\sigma=\sum_{i=1}^{N} \frac{2 G_{i}}{\alpha_{i}}\left(\lambda_{1}^{\alpha_{i}-1}-\lambda_{1}^{-0.5 \alpha_{i}-1}\right)
$$

Equation 2

For this study, $N=1$, since a 1 -term Ogden function was sufficient to fit the data. Equation 3 shows the relationship between nominal stress and stretch ratio used, based on a 1term Ogden material:

$$
\sigma=\frac{2 G}{\alpha}\left(\lambda^{\alpha-1}-\lambda^{-0.5 \alpha-1}\right)
$$


For viscoelastic modeling, a Prony series exponential decay function was used to characterize the material law. Equation 4 shows the general Prony series equation:

$$
G_{R}(t)=G_{0}\left[1-\sum_{k=1}^{N} \bar{g}_{k}\left(1-e^{-t / \tau_{k}}\right)\right] \quad \text { Equation } 4
$$

Here, the instantaneous shear modulus $\left(G_{0}=G\right)$ is multiplied by a normalized function that models relative relaxations, $g_{k}$, at characteristic time constants, $\tau_{k}$. In this study, a 4-time constant Prony series proved to be sufficient to model the data fully and accurately. Equation 5 shows the expanded 4-time constant Prony series used:

$$
G_{R}(t)=G\left[\begin{array}{c}
1-g_{1}\left(1-e^{-t / \tau_{1}}\right)-g_{2}\left(1-e^{-t / \tau_{2}}\right) \\
-g_{3}\left(1-e^{-t / \tau_{3}}\right)-g_{4}\left(1-e^{-t / \tau_{4}}\right)
\end{array}\right] \text { Equation 5 }
$$

The results obtained from the quasi-static tests were used to determine the Ogden hyperelastic representation of the quasi-static shear moduli based on Equation 3. In fitting this data to the Ogden function, stretch ratio was calculated based on the initial length of the sample. The initial length $\left(L_{0}\right)$ was defined as the in-situ length of the tested $12 \mathrm{~mm}$ segment of the spinal cord. Since the cord shrinks once it is removed from the spinal column, a scaling factor calculation for was made for each sample using the previously measured lengths of the entire dissected cord $\left(L_{s c}\right)$ and the spinal column from which it was dissected $\left(L_{s}\right)$. This initial length calculation, $L_{0}=12^{*} L_{s} / L_{s c}$, identified what the length of the marked off $12 \mathrm{~mm}$ region was in situ. Since this initial length corresponds to the zero strain state, stretch ratio is calculated starting from when the spinal cord reaches this length.

For the viscoelastic tests, $L_{0}$ was calculated the same way as done for the quasistatic test. Each cord was stretched exactly $7.5 \%$ based on its $\mathbf{L}_{0}$. The relaxation portion 
was then used to calculate the relative relaxations and their time constants by normalizing the relaxation portion of the stress vs. time curves and fitting them to a 4 time constant Prony series exponential decay $[5,21,23]$. 


\section{RESULTS}

\section{Strain Distribution Uniformity}

The images taken of the spinal cord for strain distribution analysis were analyzed using Microsuite analysis software. The purpose of these images was to determine the distribution of strain along the tested segment of the spinal cord in order to quantify whether different parts of the cord consistently experience varying amounts of strain [11]. In addition, the pictures assisted in making sure that the samples as a whole were actually stretching as expected. As shown in Table 1, the normalized stretch ratios for each segment are very close to one. Therefore, the strain distribution along the spinal cord region being tested was close to but not exactly uniform. While this shows that the different segments of the spinal cord did not stretch exactly the same, these values also indicate that each of the 4 divided regions stretched approximately as expected. The values show that there are no significantly consistent variations between the different regions, as well as prove that the entire spinal cord segment is stretched as intended.

\section{Spinal Cord Quasi-Static Testing Response}

The quasi-static uniaxial tensile test performed on the chick embryo spinal cords consistently produced non-linear stress-strain results. Representative samples of the stress-stretch ratio plots generated from the quasi-static test are shown in Figure 4. Throughout the quasi-static test, the spinal cords often exhibited what could be explained as micro-tears resulting in very small fractional drops in load. Generally however, the curve as a whole would continue to rise until a final unrecoverable drop in load corresponding to failure. One-way ANOVA analysis was performed on all the samples tested and showed a significant difference in ultimate tensile stress (UTS) among the different embryological days $(P<0.05)$. Consequently, post hoc analysis (Fisher's Least Significant Difference test) was performed for specific pairwise analysis 
Table 1

\begin{tabular}{|c|c|c|c|c|c|c|c|c|}
\hline \multicolumn{7}{|c|}{ STRAIN DISTRIBUTION UNIFORMITY } \\
\hline & $\mathbf{1 - 2}$ & Stdev & $\mathbf{2 - 3}$ & Stdev & $\mathbf{3 - 4}$ & Stdev & $\mathbf{4 - 5}$ & Stdev \\
\hline E-18 & 1.02 & 0.061 & 0.99 & 0.03 & 0.98 & 0.068 & 1.01 & 0.03 \\
\hline E-16 & 1.05 & 0.057 & 0.99 & 0.032 & 0.97 & 0.032 & 1.01 & 0.067 \\
\hline E-15 & 1.00 & 0.043 & 0.99 & 0.040 & 0.99 & 0.043 & 1.02 & 0.060 \\
\hline E-14 & 1.00 & 0.027 & 0.99 & 0.031 & 1.00 & 0.035 & 1.01 & 0.047 \\
\hline
\end{tabular}

Table-1: Normalized stretch ratio values of each segment for E18, E16, E15 and E14. These values show that while the spinal cord does not stretch exactly uniformly, it is very close. The values also show that the spinal cord as a whole stretches as intended. 


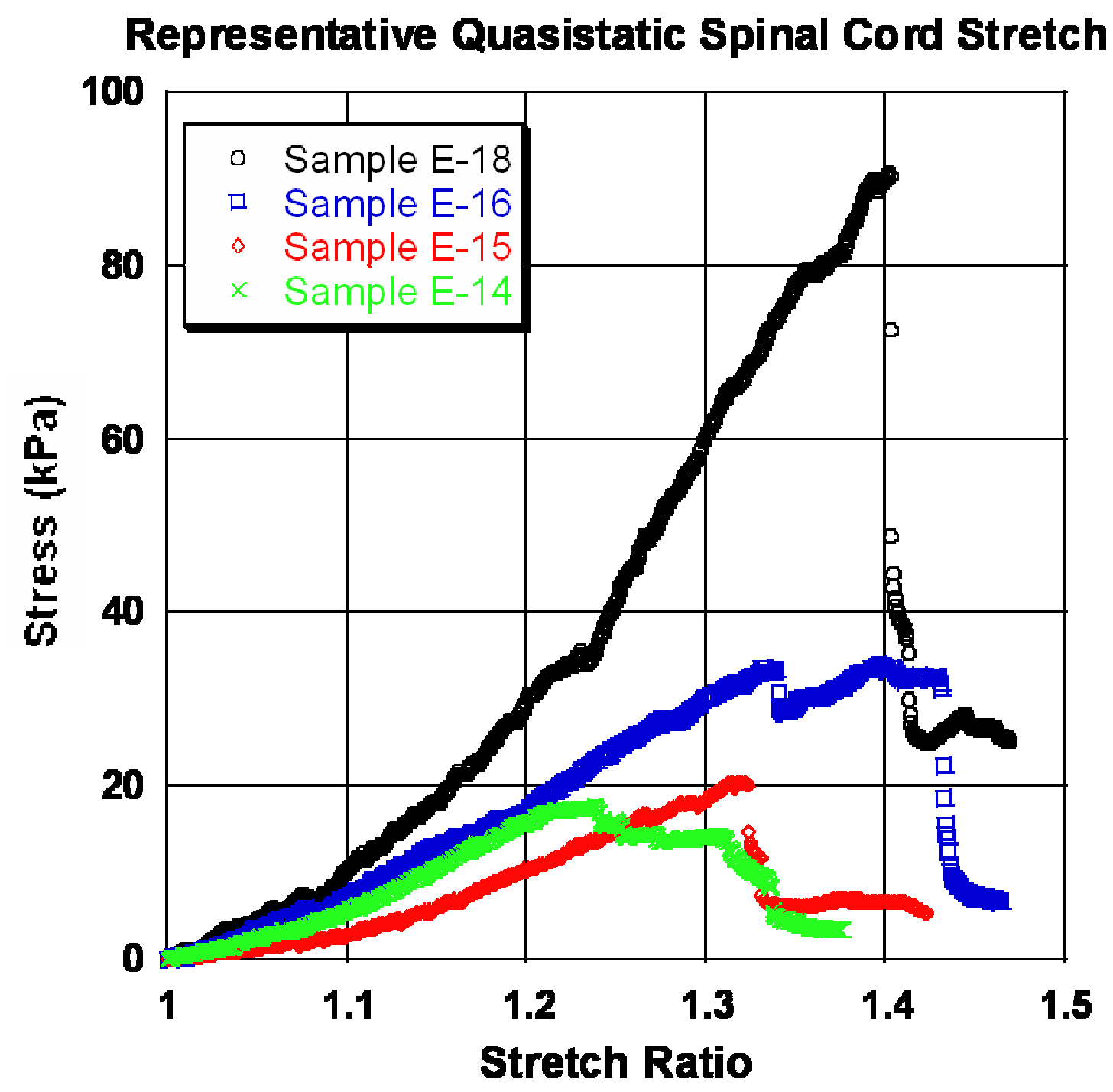

Figure-4: Representative stress-stretch ratio quasi-static response for each of the four embryological days tested in uniaxial tension to failure. All spinal cords were tested at $0.012 \mathrm{~mm} / \mathrm{sec}$ corresponding to approximately $0.001 \mathrm{~s}^{-1}$. 
and showed a significant difference in UTS between all the embryological days tested except between E16 and E15 $(P=0.220)$ and E15 and E14 $(P=0.217)$. As shown in Table 2, the ultimate tensile stress for all four developmental days tested were within the kilopascal range. E18 demonstrated the most non-linear response of the four development days tested, which may have resulted from being able to withstand a much higher ultimate tensile stress.

The elastic portion of the stress-stretch ratio plot for each sample was identified by fitting a line to the linear portion of the curve and identifying where the curve began to significantly deviate from this line, similar to a yield point. This region of the curve was individually fit to a 1-term Ogden function using Kaleidagraph.

The quasi-static material parameters, $G$ and $\alpha$ shown in Table 3, were calculated from this fitting. A 1-term Ogden function was sufficient to fit the elastic portion of the data with a very high correlation level. $G$ in the function represents the shear modulus and $\alpha$ introduces nonlinear behavior. Figure 5 shows the averaged Ogden fits for each day tested. One way ANOVA analysis was performed on these material parameters, and there was a significant difference in the shear modulus among the different days $(P=$ 0.020). With respect to the measure of linearity, there was a difference on average among the days but it was not significant $(P=0.583)$. Post hoc analysis (Fisher's Least Significant Difference test) was therefore performed on the shear modulus values and showed a significant difference between E15 and E16 $(P=0.031)$ and between $\mathrm{E} 15$ and $\mathrm{E} 18(P=0.003)$. Although a significant difference was not observed between $\mathrm{E} 14$ and E18, the relatively low $\mathrm{P}$-value $(P=0.088)$ suggests that testing more samples may overcome the variability inherent in testing biological tissues. Figure 6 shows the values and trends of both Ogden parameters for each day. 
Table 2

\begin{tabular}{|c|c|c|c|c|c|}
\hline \multicolumn{6}{|c|}{ SPINAL CORD ULTIMATE TENSILE STRESS \& STRETCH } \\
\hline & $\begin{array}{c}\text { Stretch at } \\
\text { UTS }\end{array}$ & $\begin{array}{c}\text { Standard } \\
\text { Error }\end{array}$ & $\begin{array}{c}\text { Strain at } \\
\text { UTS }\end{array}$ & UTS (kPa) & $\begin{array}{c}\text { Standard } \\
\text { Error }\end{array}$ \\
\hline E-18 & 1.43 & 0.024 & 0.522 & 69.93 & 6.97 \\
\hline E-16 & 1.37 & 0.035 & 0.438 & 38.18 & 2.33 \\
\hline E-15 & 1.42 & 0.047 & 0.508 & 30.69 & 2.71 \\
\hline E-14 & 1.26 & 0.018 & 0.293 & 22.91 & 1.60 \\
\hline
\end{tabular}

Table-2: Average Ultimate Tensile Stress and Stretch for E18, E16, E15 and E14. All four days tested had an ultimate tensile stress within the kilopascal range. 
Table 3

\begin{tabular}{|c|c|c|c|c|c|c|}
\hline \multicolumn{7}{|c|}{ SPINAL CORD OGDEN HYPERELASTIC CONSTANTS } \\
\hline & G (kPa) & $\begin{array}{c}\text { Standard } \\
\text { Error }\end{array}$ & $\alpha$ & $\begin{array}{c}\text { Standard } \\
\text { Error }\end{array}$ & $\mathbf{R}^{2}$ & $\begin{array}{c}\text { Standard } \\
\text { Error }\end{array}$ \\
\hline E-18 & 29.11 & 3.62 & 7.57 & 0.535 & 0.993 & - \\
\hline E-16 & 24.81 & 2.58 & 7.13 & 0.359 & 0.995 & - \\
\hline E-15 & 15.58 & 1.91 & 7.84 & 0.633 & 0.992 & - \\
\hline E-14 & 21.93 & 2.83 & 8.25 & 0.772 & 0.990 & - \\
\hline
\end{tabular}

Table-3: Averaged spinal cord Ogden hyperelastic constants for E18, E16, E15 and E14. 


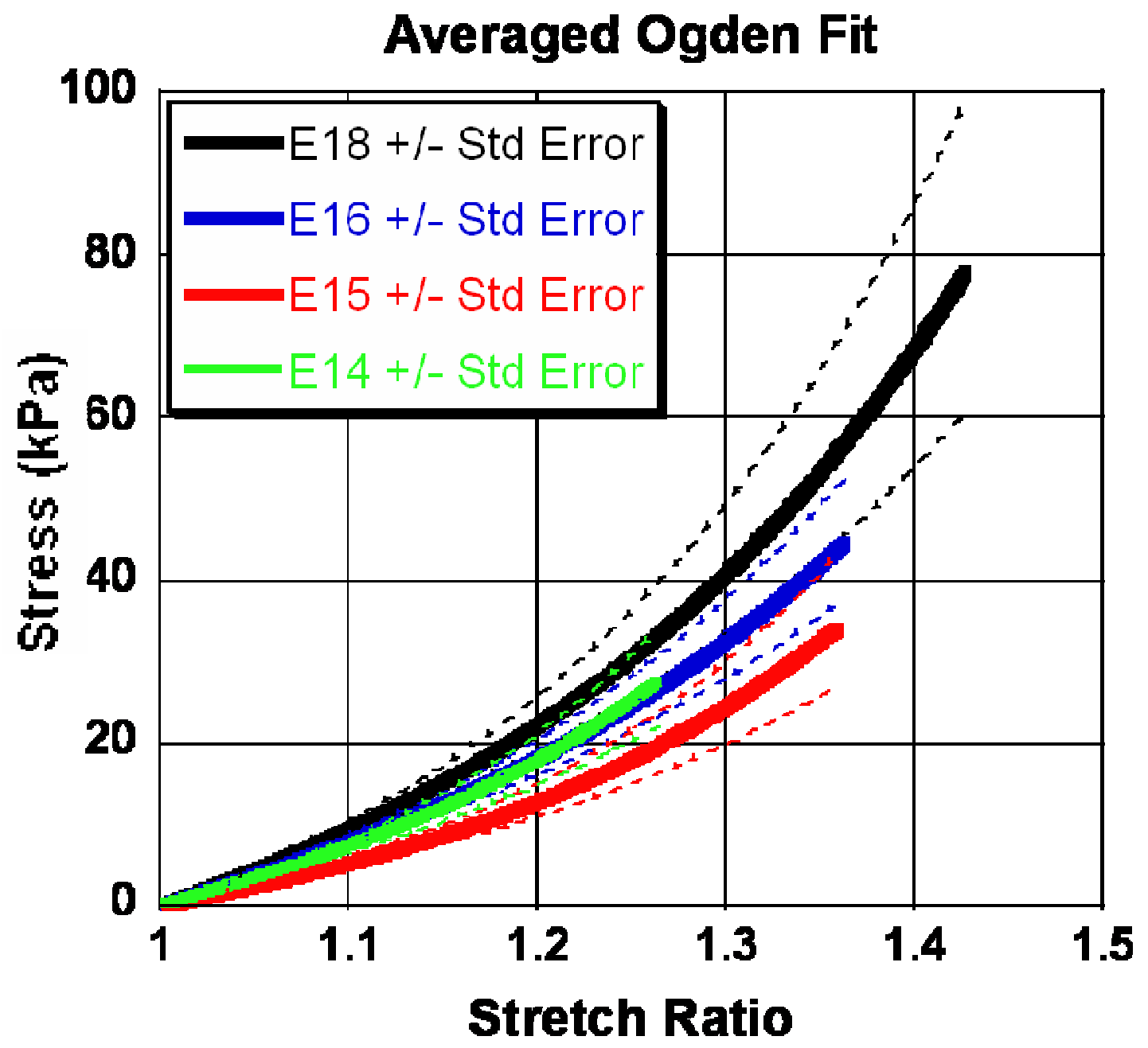

Figure-5: Averaged Ogden Parameter fits from quasi-static properties for E18, E16, E15 and E14 +/- their respective standard errors. 


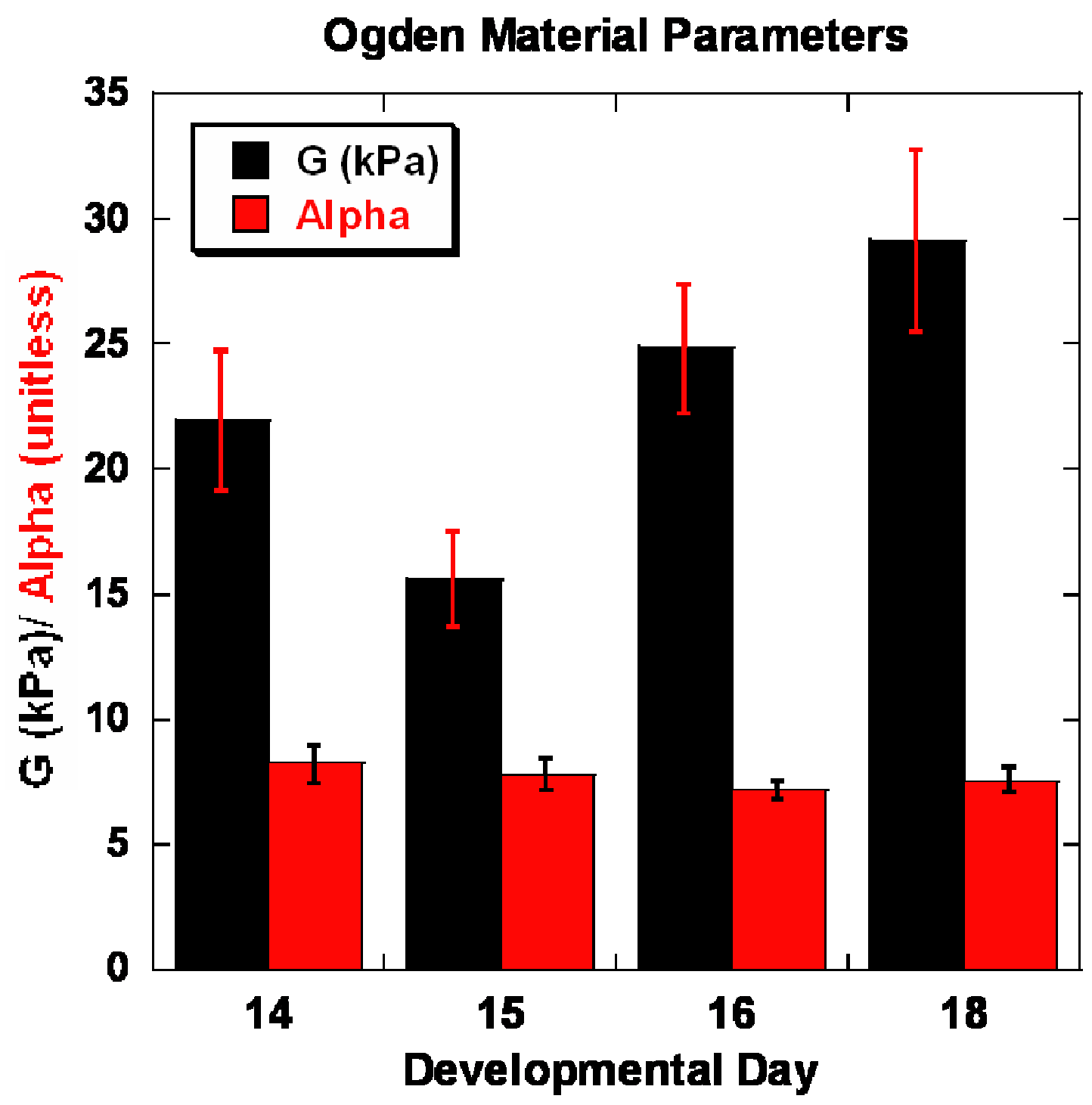

Figure-6: Average Ogden hyperelastic material parameters for the spinal cord for E18, E16, E15 and E14. 


\section{Spinal Cord Viscoelastic Testing Response}

To simulate the high strain rates experienced during trauma and identify a robust, time-dependent viscoelastic response of the spinal cord, high strain rate tests were performed. The maximum reproducible rate feasible with the Enduratec was approximately $245 \mathrm{~mm} / \mathrm{sec}\left(\sim 19.5 \mathrm{~s}^{-1}\right)$ to $7.5 \%$ stretch, which was then held for 10 seconds. Figure 7 shows the commanded function for the viscoelastic ramp and hold as well as the actual test that the Enduratec was capable of producing. The commanded ramp was $500 \mathrm{~mm} / \mathrm{sec}$, which yielded the actual slope of $245 \mathrm{~mm} / \mathrm{sec}$. The relaxation portion of the data was normalized to the maximum load reached and the normalized decay curve was fit to a 4-time constant Prony exponential decay series using Kaleidagraph. The 4-time constant Prony series captured the immediate decay time constants accurately as well as the full scale decay time constants.

Figure 8 shows a sample of the normalized decay curve for each embryological day tested. The percent stress that relaxed over the 10 second interval for which the stretch was maintained was approximately the same across the board. On average, E18 relaxed about $73.5 \%$ in total while $\mathrm{E} 16$ relaxed $72.4 \%$, E15 fell $71.7 \%$ and $\mathrm{E} 14$ relaxed $72.6 \%$. One way ANOVA analysis showed that there was no significant difference among these four relaxation totals $(P=0.786)$. Similarly to the total relaxation, one way ANOVA also showed no significant differences between the individual decay $\left(g_{\mathrm{k}}\right)$ and time $\left(\tau_{k}\right)$ constants for each day as well ( $\min g P=0.072$; $\left.\min \tau P=0.288\right)$. Interestingly, despite the lack of significant difference in the overall decay for each day, there was a significant difference in the maximum stress reached among the groups $(P=0.003)$. Post hoc analysis of these data (Fisher's Least Significant Difference test) was therefore performed for pairwise differences and showed E18 to be significantly different than E16 $(P=0.002), \mathrm{E} 15(P=0.001)$, and E14 $(P=0.002)$. In addition, while not significantly 
different, the slope of the ramp portion for E15 was less than that of E14 and E16 on average. A sample of the ramp slopes from each day tested is shown in Figure 9.

Table 4 shows the Prony series decay and time constants in detail for all the days. Approximately $68 \%$ of the total relaxation occurs in the first $30 \mathrm{~ms}$ with the other $30 \%$ relaxing over the next five to six seconds. The average Prony series fit for each of the days tested is shown in Figure 10. 


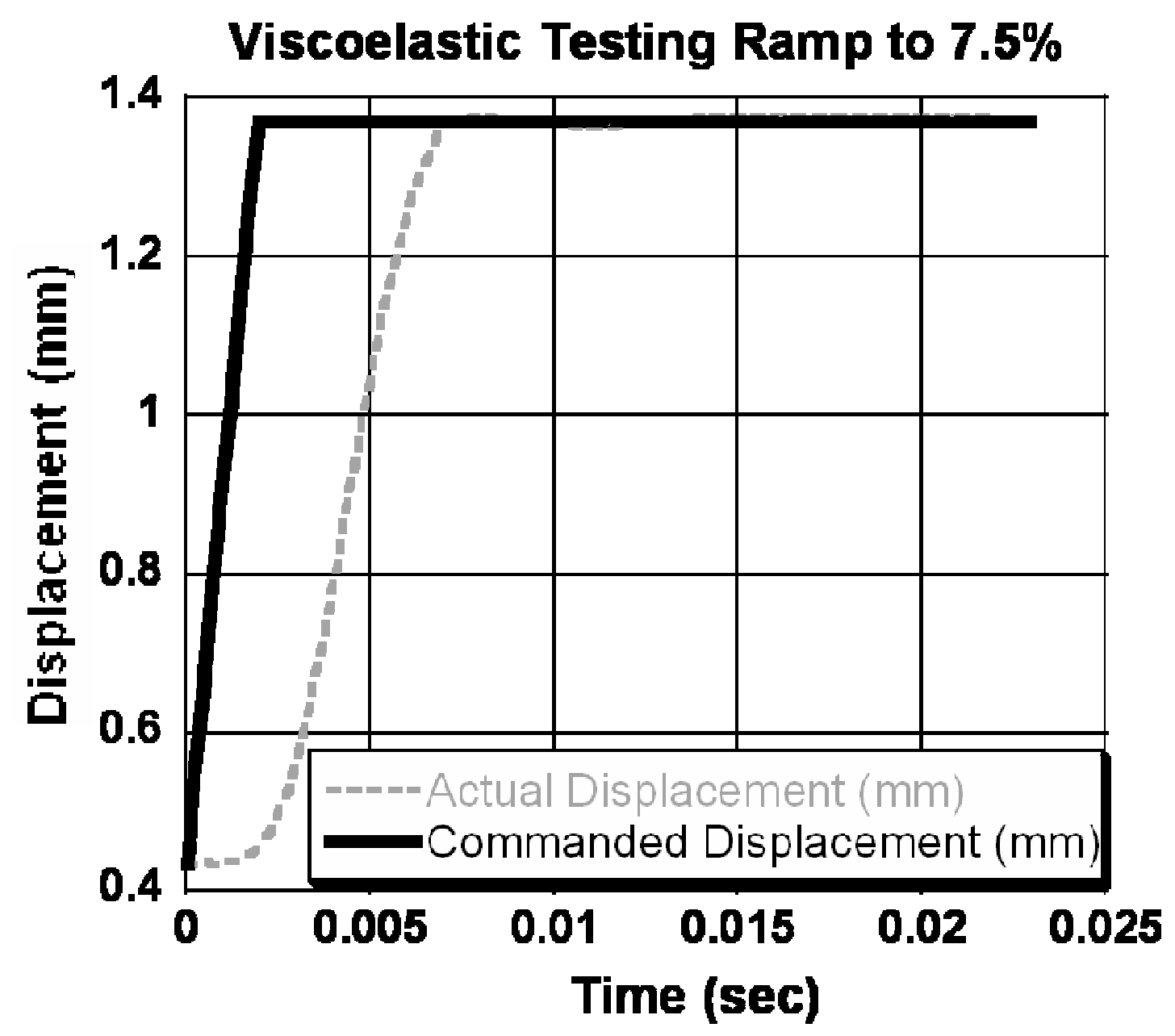

Figure-7: A plot of the commanded function run for the viscoelastic test vs. the actual resulting test. A $500 \mathrm{~mm} / \mathrm{sec}$ ramp is programmed, which results in an actual ramp of $245 \mathrm{~mm} / \mathrm{sec}$. The ramp to $7.5 \%$ stretch is held for 10 seconds. 


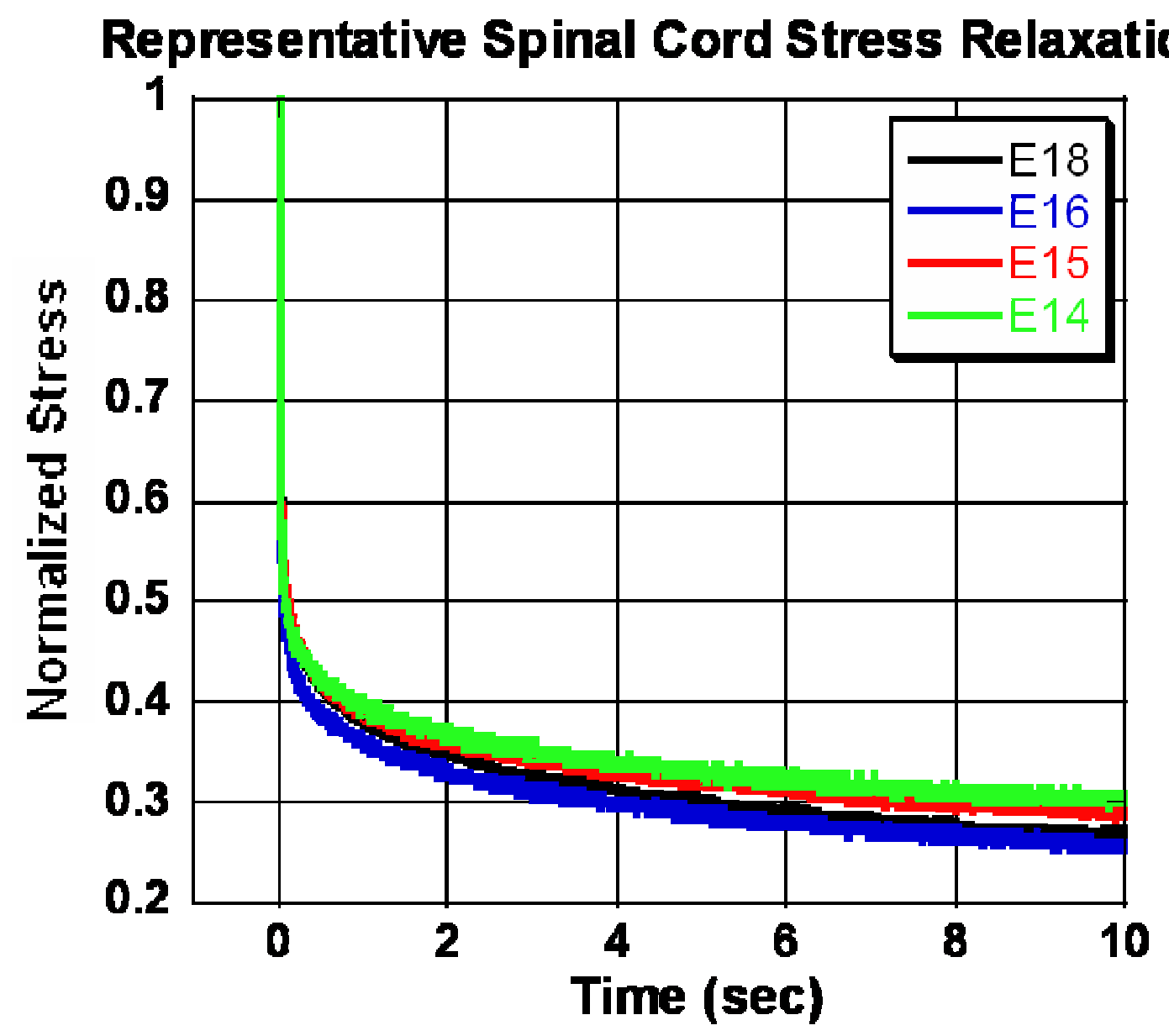

Figure-8: Representative viscoelastic stress relaxation response for each of the four embryological days tested. The spinal cords were ramped to $7.5 \%$ stretch at approximately $19.5 \mathrm{~s}^{-1}$ (varying minimally from test to test) and held for 10 seconds. 
Representative Viscoelastic Test Ramp Response

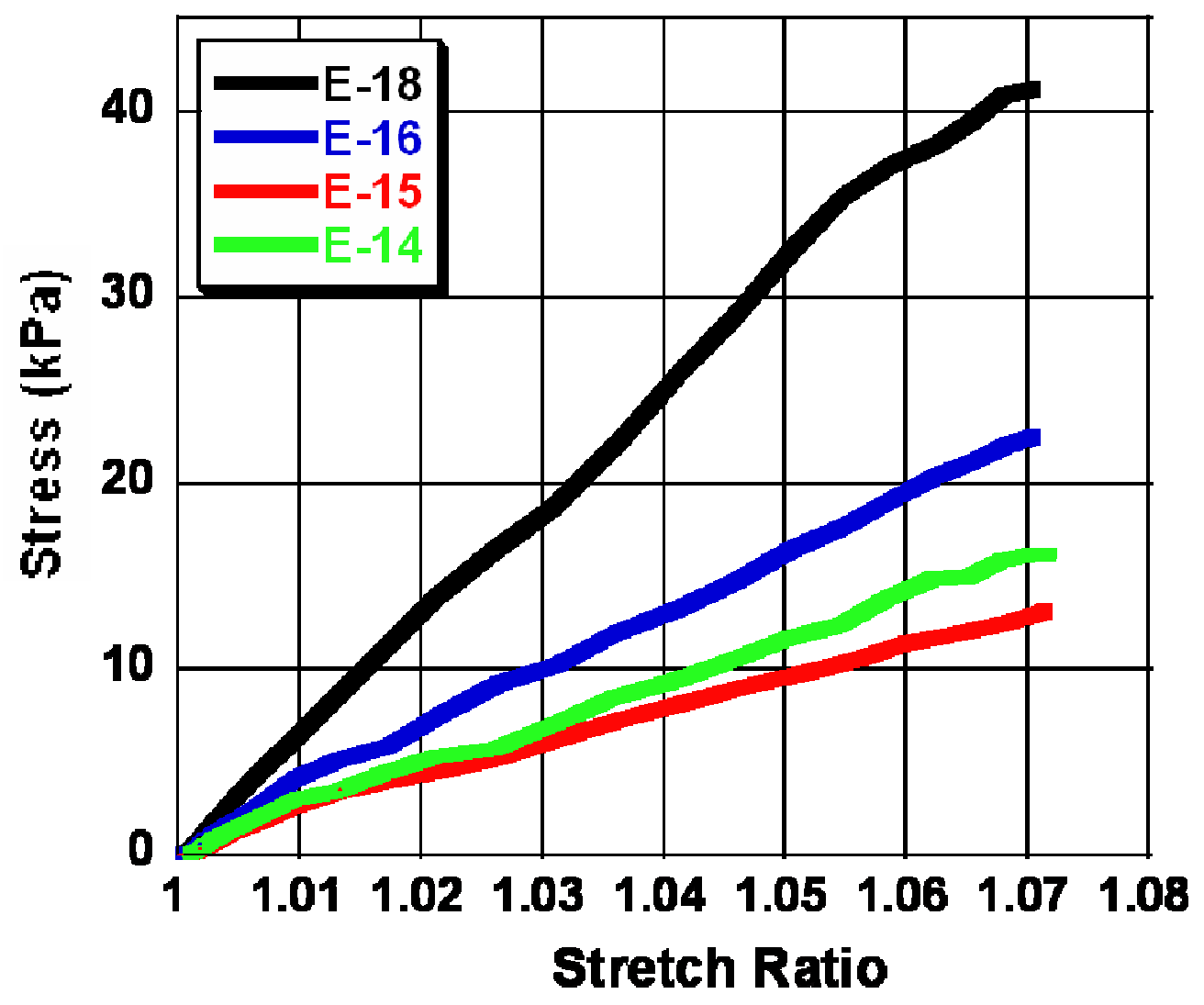

Figure-9: Representative viscoelastic ramp response for E18, E16, E15, and E14. ANOVA analysis showed E18 ramp to be significantly different that the rest of the days. Differences between E16, E15 and E14 were not significant. 


\section{Table 4}

\begin{tabular}{|c|c|c|c|c|c|c|c|c|}
\hline \multicolumn{9}{|c|}{ SPINAL CORD VISCOELASTIC CONSTANTS } \\
\hline & $E-18$ & $\begin{array}{l}\text { Std } \\
\text { Error }\end{array}$ & $E-16$ & $\begin{array}{l}\text { Std } \\
\text { Error }\end{array}$ & E-15 & $\begin{array}{l}\text { Std } \\
\text { Error }\end{array}$ & E-14 & $\begin{array}{l}\text { Std } \\
\text { Error }\end{array}$ \\
\hline$g_{1}(\mathrm{kpa})$ & 0.260 & 0.013 & 0.262 & 0.016 & 0.278 & 0.014 & 0.309 & 0.012 \\
\hline$\tau_{1}(\mathrm{sec})$ & 0.002 & 0.000 & 0.002 & 0.000 & 0.002 & 0.000 & 0.002 & 0.000 \\
\hline$g_{2}(\mathrm{kpa})$ & 0.225 & 0.010 & 0.232 & 0.010 & 0.215 & 0.009 & 0.207 & 0.007 \\
\hline$\tau_{2}(\mathrm{sec})$ & 0.032 & 0.003 & 0.026 & 0.002 & 0.031 & 0.002 & 0.029 & 0.002 \\
\hline$g_{3}(\mathrm{kpa})$ & 0.104 & 0.004 & 0.096 & 0.006 & 0.100 & 0.005 & 0.091 & 0.003 \\
\hline$\tau_{3}(\mathrm{sec})$ & 0.424 & 0.020 & 0.401 & 0.015 & 0.460 & 0.039 & 0.409 & 0.019 \\
\hline$g_{4}(\mathrm{kpa})$ & 0.146 & 0.010 & 0.133 & 0.006 & 0.124 & .006 & 0.119 & 0.005 \\
\hline$\tau_{4}(\mathrm{sec})$ & 5.007 & 0.257 & 5.071 & 0.224 & 5.727 & 0.583 & 5.028 & 0.211 \\
\hline $\begin{array}{c}g_{1}+g_{2}+ \\
g_{3}+g_{4} \\
(\mathrm{kPa})\end{array}$ & 0.7353 & 0.016 & 0.724 & 0.011 & 0.717 & 0.012 & 0.726 & 0.010 \\
\hline $\mathbf{R}^{2}$ & .998 & - & .996 & - & 0.993 & - & 0.992 & - \\
\hline
\end{tabular}

Table-4: Average Prony series exponential decay stress relaxation and time constants for E18, E16, E15 and E14. 

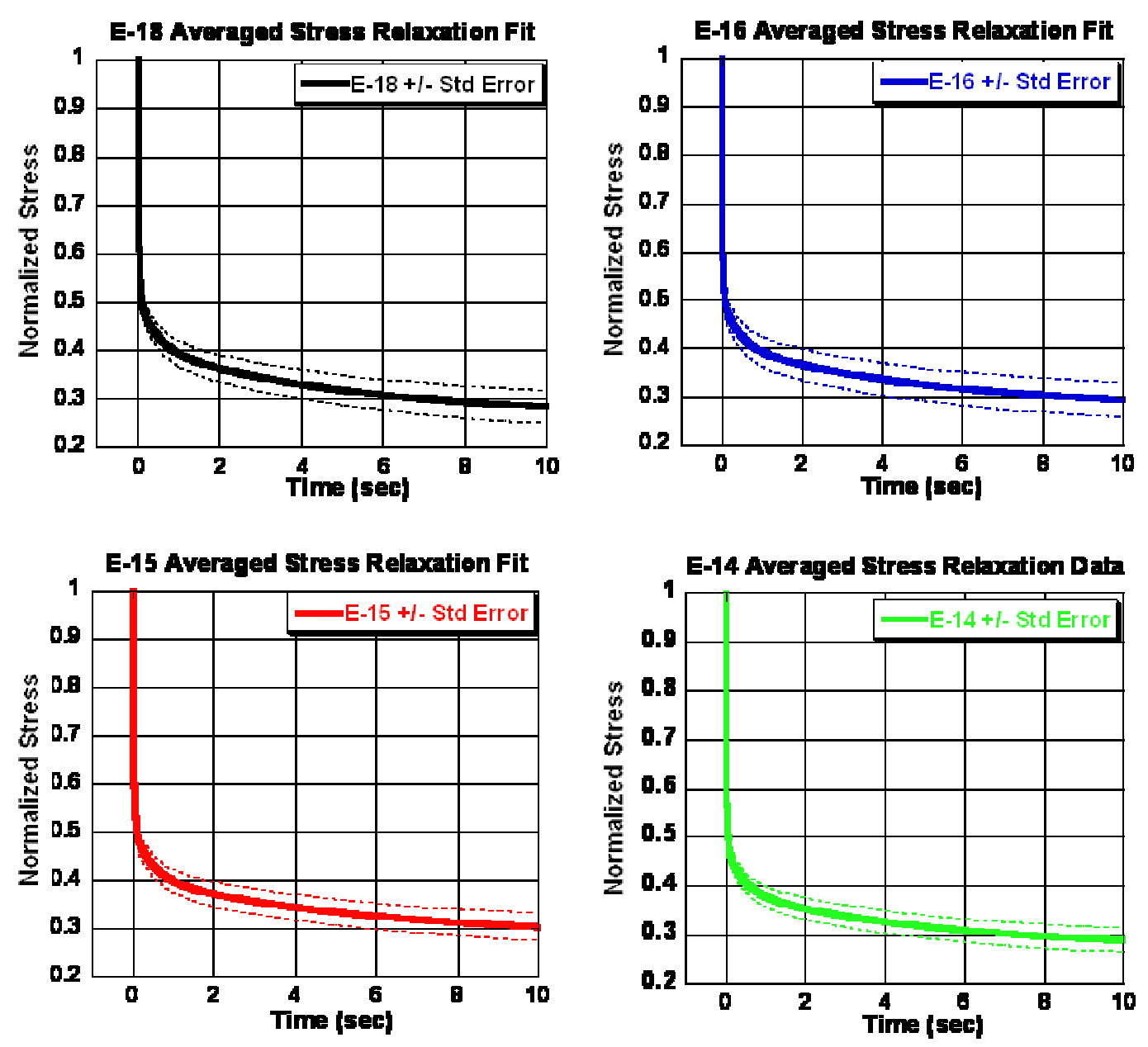

Figure-10: Averaged Prony series exponential decay fits for E18, E16, E15 and E14 +/-standard errors. All four curves decay approximately $72 \%$ with $68 \%$ of it occurring in the first $30 \mathrm{~ms}$. 


\section{DISCUSSION}

The focus of this study was to investigate the mechanical properties of the chick embryo spinal cord along different days of development. Therefore, the quasi-static and viscoelastic properties of the spinal cord were determined and analyzed among four developmental days (E14, E15, E16, and E18). The development of the chick spinal cord along these days parallels the development of the human fetus and post-natal human infant. Hence, this work may aid future projects in correlating these results to human development. The significance of such findings range from adequately describing age-specific material characteristics, determining age specific injury tolerance, as well as aiding stem cell research in finding treatment for neurodegenerative conditions.

Since all spinal cord testing was done with excised tissue, special care was taken in order to maintain the highest correlation possible between these results and the true in vivo properties. Consequently, all samples were tested immediately after extraction from the spine. In addition, since biological tissues dehydrate relatively quickly, which would render the results inaccurate, all samples were kept constantly hydrated via an ultrasonic mister. Through the process of many trial tests, the fine spray ultrasonic mister was found to allow for more consistent and accurate results than any other feasible hydration method. Via this mister, all samples tested were kept equally and fully hydrated. Special care was also taken to maintain spinal cord laxity (never stretched) prior to testing including always holding a sample from both ends to prevent any deformation under its own weight.

\section{Experimental Variability}

In spite of all the measures taken for this testing, there was still some variability in our results, which is not surprising considering the sources of error that are difficult to control and/or eliminate. The experimental setup in its entirety involves many critical 
steps, each of which may introduce some variability. From the start, no two chicks will have identical embryological development. Differences in the "freshness" of eggs may affect the exact developmental progress among different eggs [14]. Such differences include the lapse of time between laying and incubation, the temperature of the eggs when placed in the incubator, the size of each individual egg or even seasonal differences. Consequently some degree of variability in the overall development, and therefore in the spinal cord development and properties, is expected.

Another possible source of variability stems from the pretension in the spinal cord while in situ. Each spinal cord is stretched uniquely while still attached to the spinal column and shrinks accordingly when taken out. Therefore between two samples tested on the same day with different shrink percentages, properties will vary. Furthermore, since each spinal cord shrinks a unique amount while the stretch rate was always set to $0.012 \mathrm{~mm} / \mathrm{sec}$, the actual strain rate for each cord is different by a very minimal amount. While the differences in the strain rates were negligible, a minor source of variability may have been introduced in this step.

In addition, the dura mater, which is the outermost and most substantial of the three meningeal layers surrounding the spinal cord [26], was never removed. Although no studies of pre-natal or infant dura mater have been performed, most research, including our own work with adult rat spinal cord dura mater, indicate that the dura is typically significantly stiffer than the spinal cord tissue it surrounds [5],[17],[19]. However, due to the fragility of the spinal cord, the samples were tested with the dura mater intact and differences in the dura mater itself may ultimately have affected the results seen in the tests as well. Lastly, while the thoracic region was the main section tested, another source of scatter may have resulted from differences in the exact vertebral levels tested. A $12 \mathrm{~mm}$ segment was tested for each spinal cord and since the length of the spinal cord 
increases significantly during the developmental period studied [16], the exact vertebral levels comprising this $12 \mathrm{~mm}$ segment will change with development.

\section{Spinal Cord Quasistatic Testing}

A low strain rate was used to ascertain measurement of the quasistatic properties of the spinal cord. The quasistatic E18 ultimate tensile stress of $70 \mathrm{kPa}$ is less than the previously reported 1.02MPa UTS of the human cervical spinal cord [5]. The cervical spinal cord however was tested at more than double the strain rate used in our study. On the other hand, the E18 UTS is comparable to the $80 \mathrm{kPa}$ previously found in preliminary quasistatic testing on rat spinal cords [11]. However, whereas the rat spinal cord failed at $12 \%$ strain, the chick E18 spinal cord failed at approximately $52.25 \%$ strain. The rest of the embryonic chick spinal cords tested all had ultimate tensile stresses within the kilopascal range as well.

The spinal cords exhibited the typical nonlinear j-shaped curve associated with biological tissues. The slow rise to the stress-strain curve is thought to be the result of mostly unaligned and wavy fibers, which straighten out and align under tensile loading. This results in the initially compliant response which then becomes progressively stiffer as more fibers start to bear the tensile load [5]. Previous work has shown that axons in the spinal cord and other central nervous system tissue are wavy $[4,6]$. Hao and Shreiber recently showed that the waviness of axons in the chick embryo spinal cord changes during the same developmental period studied herein [16]. Interestingly, that study also demonstrated that the kinematic coupling of axons changes during development which will change the composite behavior of the spinal cord tissue. Subsequent studies were performed with E18 spinal cords that were demyelinated by injecting with either ethidium bromide, which kills astrocytes and oligodendrocytes, or with an antibody against GalC, which delays differentiation of oligodendrocyte precursor into mature myelinating cells [15]. In both cases, the stiffness of the demyelinated spinal 
cord was decreased compared to vehicle controls (saline injection for ethidium bromide, and rabbit IgG for anti-GalC). Additionally, the ultimate tensile stress for spinal cords demyelinated with ethidium bromide was significantly decreased. Together with our results, these studies indicate that maturation of the glial matrix, including astrocyte and oligodendrocyte coupling of axons, can change not just the neurophysiological environment but the mechanical environment as well.

Although the shear modulus among different developmental days was significantly different, post hoc analysis was unable to isolate those significant differences among specific pairwise comparisons. Previously, rat brain properties have been examined over a staggered range of developmental days. In that study, significant differences were not observed in the shear modulus of brain tissue among all pairs of ages tested (postnatal day 13, 17, 43 and 90). Day 13 and 17 (group 1) were similar, and day 43 and 90 (group 2) were similar [13], and significant differences were seen between those two groups. A similar trend is seen in this study in that E14 and E15 shear moduli were not significantly different and neither were E16 and E18 stiffness values. E18 and E16 however, were both significantly stiffer than E15, and E18 was also significantly stiffer than E14.

E18 was the stiffest and most nonlinear of all the days tested and also had the highest ultimate tensile stress. By E18, the spinal cord has more than $50 \%$ of its axons myelinated compared to only $16 \%$ by E15. This increase along with the growth of neural and vascular tissues that are surrounded by and interwoven with connective tissues influence such stiffness [5]. E16 also shows significantly stiffer properties than E15 although the hyperelastic curve is not as pronounced since the E16 cord fails earlier than E18. In addition, E14 was as stiff as E16 on average and stiffer than E15 on average although not significantly. 
While it may seem puzzling that the relationship of E14 to E15 opposes the general trend of increasing stiffness with development, it is necessary to think of the developmental changes between these days. Vasculature and cell differentiation are increasing at an exponential rate throughout these days [27]; myelination of axons is also increasing rapidly. It is feasible that inter-cellular connections are initially weakened while cells differentiate, which would explain a slight decrease in stiffness. While this may be a process that occurs continuously, myelination of the axons increases much more significantly after E15 which in turn would then overshadow this effect of cell differentiation. Further histological investigation between E14, E15 and E16 would be required to better explain these results. We do however believe this result to be accurate since similar results between the stiffness of E14, E15 and E16 were seen in the ramp portion of the viscoelastic test.

These results may correlate to specific patterns of growth and differentiation, since it is known that both are dependent on the mechanical properties of the extra cellular environment. Neurite growth and branching is greater on compliant 2D substrates than stiff ones [12], and work in our laboratory has shown that neurite growth from chick embryo dorsal root ganglia can be enhanced and directed by a gradient of mechanical properties from stiff (G 200Pa) to soft (G 60Pa) [24]. Thus, the period between E14 and E16 may represent a critical time when specific axon tracts or dendritic fields are being established. Additionally, these same mechanical properties are required for stem cells to grow and differentiate appropriately. For example, the mechanical boundary conditions placed on mesenchymal stem cells (MSC's) are known to alter their gene expression pattern and consequently their functional behavior [18]. Therefore, once placed into different mechanical environments, MSC's can differentiate into osteoblasts and chondrocytes (mesenchymal cells) or into endothelial cells and neural cells (non-mesenchymal cells) [18]. Other in vitro work suggests that a compliant 
substrate may be a principal factor in driving stem cell differentiation into neural lineages [9]. Consequently, the dip in stiffness from E14-E16 may represent a natural adaptation to assist in control of the differentiation of specific classes of neurons and/or glia.

Regardless, there does remain the possibility of an inaccuracy in the E14 data. Since, E14 spinal cords were the most delicate and therefore the hardest of all the days to test, they may have been pre-stretched throughout the procedure leading up to testing without notice. It is possible that the E14 spinal cords deform under their own weight during sample preparation. Consequently, while sacrificing the chicks at this age, the dangling head may have stretched the spine along with the spinal cord. Stretching of the spinal cord would align fibers (such as collagen for example) from a slack formation to a somewhat aligned and stretched formation. This could then cause the increased stiffness seen in the data.

\section{Spinal Cord Viscoelastic Testing}

To understand the underlying biomechanics of spinal cord injury, it is necessary to identify the properties of the spinal cords at the extremely high loading rates experienced during trauma. Because of this extremely high loading rate, the samples were only ramped to $7.5 \%$ stretch, in order to limit sample failure. This stretch was chosen after analyzing the quasistatic data and finding that E14 spinal cords fail as early $25 \%$ stretch. All spinal cords exhibited very significant, immediate relaxation. Regardless of how much stress was generated in the ramp phase of the test for each day, they all relaxed about $72.5 \%$ with approximately $68 \%$ of this decay occurring within the first $30 \mathrm{~ms}$. These results indicate that while stiffness of the developing chick spinal cord increases with development, the viscoelastic properties remain the same. Previous stress-relaxation tests performed on human cervical spinal cords at physiological loading levels showed relaxation times in both the decades of $0.1-1 \mathrm{sec}$ and $1-10 \mathrm{sec}$ [5]. While this current study performed at traumatic loading rates also shows relaxation times in the 
1-10 sec decade, it definitively shows the majority of its relaxation within the first few hundred milliseconds. These studies suggest strongly that more tests be performed on adult tissue in species commonly used for modeling $\mathrm{SCl}$ experimentally, such as the rat, and on human tissue, as the current data in the literature for these species severely underestimates the relaxation response of spinal cord tissues. As such, studies of injury biomechanics may be significantly inaccurate. However, for other modeling of spinal tissue biomechanics, such as virtual or robotic surgeries, or the response to changes in CSF pressure, further studies may require studying relaxation for longer hold times than the $10 \mathrm{sec}$ performed herein to truly examine the quasistatic properties.

\section{Summary}

Overall, this study finds that the quasistatic mechanical properties of the developing chick embryo spinal cord do change among E14 and E18. Stiffness of the spinal cord is within the kilopascal range for all four days tested with E18 being the stiffest. Viscoelastic properties however do not change among the days tested as all four days relaxed approximately $72.5 \%$ with $68 \%$ of it occurring within the first $30 \mathrm{~ms}$. 


\section{REFERENCES}

[1] P.L. Altman, D.S. Dittmer, Growth Including Reproduction and Morphological Development, Federation of American Societies for Experimental Biology, Washington, 1962.

[2] E.S. Anderson, C. Bjartmar, C. Hildebrand, Myelination of prospective large fibres in chicken ventral funiculus, J Neurocytol 29 (10) (2000) 755-764.

[3] A.C. Bain, D.F. Meaney, Tissue-level thresholds for axonal damage in an experimental model of central nervous system white matter injury, J Biomech Eng 122 (6) (2000) 615-622.

[4] A.C. Bain, D.I. Shreiber, D.F. Meaney, Modeling of microstructural kinematics during simple elongation of central nervous system tissue, J Biomech Eng 125 (6) (2003) 798-804.

[5] L.E. Bilston, L.E. Thibault, The mechanical properties of the human cervical spinal cord in vitro, Ann Biomed Eng 24 (1) (1996) 67-74.

[6] A. Breig, Biomechanics of the Central Nervous System, Almqvist \& Wiksell, Stockholm, 1960.

[7] D.I. Bylski, T.J. Kriewall, N. Akkas, J.W. Melvin, Mechanical behavior of fetal dura mater under large deformation biaxial tension, J Biomech 19 (1) (1986) 1926.

[8] I.M. Calder, I. Hill, C.L. Scholtz, Primary brain trauma in non-accidental injury, J Clin Pathol 37 (10) (1984) 1095-1100.

[9] D.E. Discher, P. Janmey, Y.L. Wang, Tissue cells feel and respond to the stiffness of their substrate, Science 310 (5751) (2005) 1139-1143.

[10] J. Dobbing, The later development of the brain and its vulnerability, Scientific Foundations of Paediatrics, Heiemann Medical, London, 1981, pp. 744-759.

[11] R.J. Fiford, L.E. Bilston, The mechanical properties of rat spinal cord in vitro, J Biomech 38 (7) (2005) 1509-1515.

[12] L.A. Flanagan, Y.E. Ju, B. Marg, M. Osterfield, P.A. Janmey, Neurite branching on deformable substrates, Neuroreport 13 (18) (2002) 2411-2415.

[13] A. Gefen, N. Gefen, Q. Zhu, R. Raghupathi, S.S. Margulies, Age-dependent changes in material properties of the brain and braincase of the rat, J Neurotrauma 20 (11) (2003) 1163-1177. 
[14] V. Hamburger, H.L. Hamilton, A series of normal stages in the development of the chick embryo. 1951, Dev Dyn 195 (4) (1992) 231-272.

[15] H. Hao, Identification of Axonal Kinematics, Rutgers, The State University of New Jersey, 2007.

[16] H. Hao, D.I. Shreiber, Axon Kinematics Change During Growth and Development, Journal of Biomedical Engineering 129 (2007) 1-13.

[17] K. Ichihara, T. Taguchi, I. Sakuramoto, S. Kawano, S. Kawai, Mechanism of the spinal cord injury and the cervical spondylotic myelopathy: new approach based on the mechanical features of the spinal cord white and gray matter, J Neurosurg 99 (3 Suppl) (2003) 278-285.

[18] G. Kasper, N. Dankert, J. Tuischer, M. Hoeft, T. Gaber, J.D. Glaeser, D. Zander, M. Tschirschmann, M. Thompson, G. Matziolis, G.N. Duda, Mesenchymal stem cells regulate angiogenesis according to their mechanical environment, Stem Cells 25 (4) (2007) 903-910.

[19] J.T. Maikos, D.I. Shreiber, Mechanical Properties of Dura Mater from the Rat Brain and Spinal Cord, Journal of Neurotrauma (Submitted).

[20] M.A. Micci, P.J. Pasricha, Neural stem cells for the treatment of disorders of the enteric nervous system: strategies and challenges, Dev Dyn 236 (1) (2007) 33-43.

[21] K. Miller, K. Chinzei, Mechanical properties of brain tissue in tension, J Biomech 35 (4) (2002) 483-490.

[22] S.P. Porterfield, C.E. Hendrich, The role of thyroid hormones in prenatal and neonatal neurological development--current perspectives, Endocr Rev 14 (1) (1993) 94-106.

[23] M.T. Prange, S.S. Margulies, Regional, directional, and age-dependent properties of the brain undergoing large deformation, J Biomech Eng 124 (2) (2002) 244252.

[24] H.G. Sundararaghavan, D.I. Shreiber, Gradients of stiffness guide neurite growth in 3D collagen gels, ASME IMECE Conference, Seattle, WA, 2007.

[25] K.L. Thibault, S.S. Margulies, Age-dependent material properties of the porcine cerebrum: effect on pediatric inertial head injury criteria, J Biomech 31 (12) (1998) 1119-1126.

[26] L.H. Weed, Meninges and Cerebrospinal Fluid, J Anat 72 (Pt 2) (1938) 181-215. 
[27] K. Whalley, P. O'Neill, P. Ferretti, Changes in response to spinal cord injury with development: vascularization, hemorrhage and apoptosis, Neuroscience 137 (3) (2006) 821-832.

[28] E. Witschi, The Development of Vertebrates, Saunders, Philadelphia, 1956. 